\title{
Esophageal carcinoma: Clinical TNM staging with endosonography and computed tomography
}

Tl Tio, MD, PhD, FCA Den Hartog Jager, MD, PPLO Coene, MD

\begin{abstract}
The prognosis of esophageal carcinoma has remained poor despite improvement of diagnostic modalities. Endosonography and computed tomography were performed for preoperative TNM staging (clinical TNM) of esophageal carcinoma. Endosonography was superior to computed tomography for diagnosing early stages and nonresectability of carcinoma. Endosonography was also superior to computed tomography in diagnosing regional lymph node metastases. For diagnosing nonmetastatic lymph nodes, however, computed tomography was superior. Endosonography was superior for diagnosing celiac lymph node metastases but less accurate in detecting liver involvement. Endosonography was accurate for clinical TNM staging of esophageal carcinoma. The possibility of performing cytology and biopsy will further enhance the diagnostic value of endosonography. Can J Gastroenterol 1990;4(9):603-607
\end{abstract}

Key Words: Clinical TNM staging, Computed tomography, Endosonography, Esophageal carcinoma

\section{Le rôle de l'endosonographie dans le cancer de l'oesophage:}

\section{La classification TNM clinique}

RESUME: Le pronostic du cancer de l'oesophage reste mauvais malgré lamélioration des modalités diagnostiques. L'endosonographie et la tomographie assistée par ordinateur ont été effectuées pour la classification pTNM (TNM clinique) des cancers de l'oesophage. L'endosonographie s'est avérée supérieure à la tomographie assistée par ordinateur dans le diagnostic des cancers aux stades précoces et de la non-résécabilité des tumeurs. L'endosonographie était également supérieure à la tomographie assistée par ordinateur pour diagnostiquer

Academic Medical Center, Department of Gastroenterology-Hepatology, Amsterdam, The Netherlands

Correspondence and reprints: Dr TL Tio, Academic Medical Center, Department of Gastroenterology-Hepatology, Meibergdreef 9, 1105 AZ Amsterdam, The Netherlands.

Telephone 020 - 5669111 , Fax 020 - 5664440
Frophageal carcinoma is usuEally diagnosed in late stages. The prognosis of advanced carcinoma is poor. Early stages of the disease are incidentally found in the evaluation of patients with dysphagia. Early esophageal carcinoma is defined as carcinoma localized in the mucosa or submucosa with no evidence of lymph node involvement. A large series of patients with early esophageal cancer was reported in China and Japan (1-5). TNM classification has been widely used for staging esophageal carcinoma (6-8). The depth of tumour infiltration is used as the criterion for staging tumour categories. The definition of regional lymph nodes has been modified and lymph node classification simplified. Computed tomography is widely used for staging esophageal carcinomas. The accuracy of computed tomography, however, is variable $(9,10)$.

Endosonography - endoscopic and nonoptic sonography via the gastrointestinal lumen - has been reported to be accurate for staging esophageal carcinoma because of its ability to image the individual layers of the gastrointestinal wall structure $(11-19)$. The 
les métastases des ganglions lymphatiques. Pour le diagnostic des ganglions lymphatiques non métastasiques, toutefois, la tomographie assistée par ordinateur était supérieure. L'endosonographie était supérieure pour le diagnostic des métastases des ganglions lymphatiques céliaques mais moins efficace dans la détection de l'atteinte hépatique. L'endosonographie s'est avérée efficace dans la classification TNM clinique des cancers de l'oesophage. La possibilité de procéder à une cytologie et à une biopsie augmente encore la valeur diagnostique de l'endosonographie.

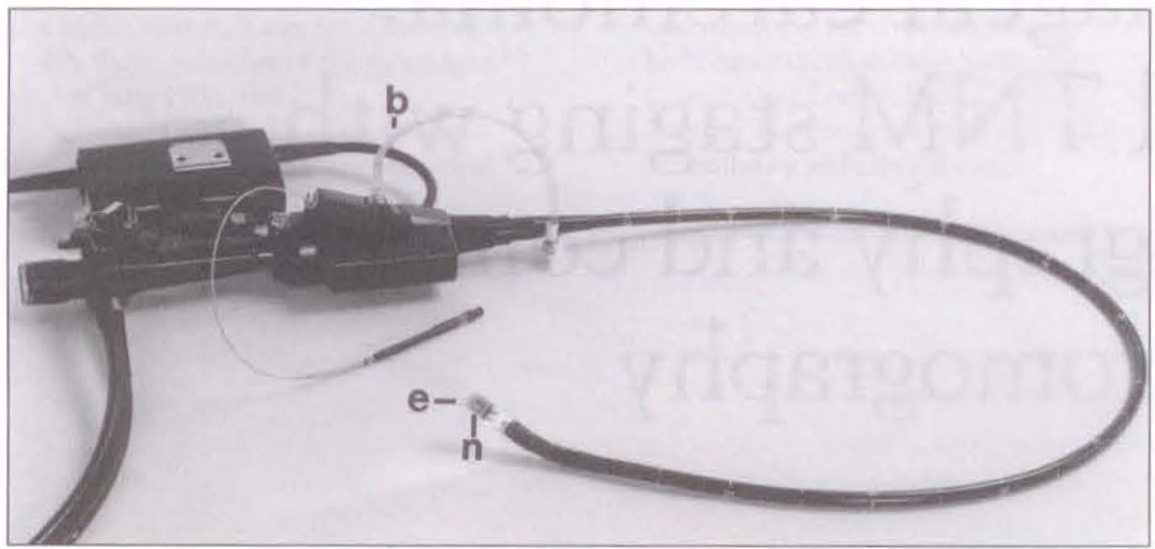

Figure 1) An Olympus echoendoscope (EU-M3) loaded with a small echoprobe (e) and a switch for changing the ultrasound frequency from 7.5 to $12 \mathrm{MHz}$. A sclerosing needle ( $n$ ) passes through the instrumental channel for aspiration cytology. $b$ Channel for filling the balloon with water

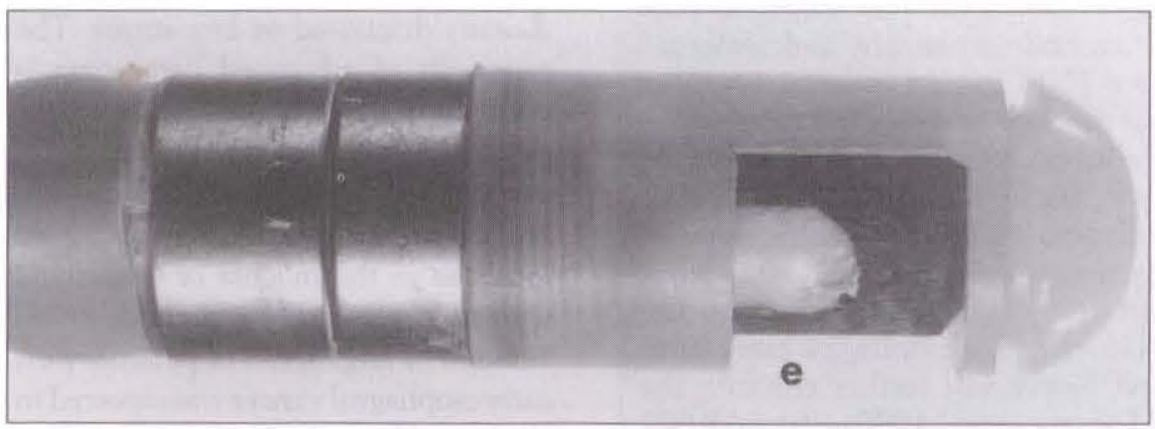

Figure 2) A flexible nonoptic Aloka ultrasonic instrument with a small echoprobe (e) at the tip authors have been using Olympusecho. endoscopes EU-M2 and EU-M3 (Figure 1). The latter emits a biopsy channelfor cytologically guided puncture or biopsy. For a nonoptic flexible instrument, the authors have been using an Aloki prototype (Figure 2 ). Recently, a small catheter echoprobe became available (Figure 3 ). Table 1 summarizes the specifications of these instruments.

\section{TECHNIQUE OF INVESTIGATION}

The investigation technique is com. parable to gastroscopy after local oro. pharyngeal anesthesia and intravenows sedation with midazolam. Sedation is necessary because of the discomfort of introducing the rigid tip of the instrument into the pharynx and insufflating the balloon fixed at the echoprobe with water. The patient is lying in the left lateral decubitus position. The instru. ment has to be introduced blindly because side-viewing optics do not allow endoscopic visualization of the esophagus. The instrument should be introduced into the stomach whenever possible to visualize the perigastric lymph nodes, particularly the celiac lymph nodes ( $\mathrm{M}=$ Distant metastasis) Images comparable to cross sectional computed tomography cuts are used for standardization of endosonography in. vestigation. The instrument is slowly withdrawn until the infiltrating abnormality with adjacent lymph nodes is imaged sonographically. In the case of severe stenosis, which toes not allow passage of the echoendoscope, a flexible

TABLE 1

Technical data of the Olympus echoendoscopes used for clinical TNM staging of esophageal carcinoma

\begin{tabular}{|c|c|c|c|c|}
\hline & EU-M2 & EU-M3 & VU-M2 (video) & Catheter echoprobe \\
\hline Endoscope & Side-viewing & Side-viewing & Side-viewing & $\begin{array}{c}\text { Forward-viewing (GIF- } \\
\quad 1710 / G \mid F-1 T 20)\end{array}$ \\
\hline Echoprobe & $\begin{array}{l}\text { Mechanical sector or } \\
\text { radial scanning } \\
\left(180^{\circ} \text { or } 360^{\circ}\right)\end{array}$ & $\begin{array}{l}\text { Mechanical sector or } \\
\text { radial scanning } \\
\left(180^{\circ} \text { or } 360^{\circ}\right)\end{array}$ & $\begin{array}{l}\text { Mechanical sector or } \\
\text { radial scanning } \\
\left(180^{\circ} \text { or } 360^{\circ}\right)\end{array}$ & $\begin{array}{c}\text { Catheter echo-probe } \\
\text { ( } 360^{\circ} \text { radial } \\
\text { scanning) }\end{array}$ \\
\hline Length ( $\mathrm{mm}$ ) & 42 & 42 & 44 & $\begin{array}{c}\text { In total } 140 \mathrm{~cm} \text { with the } \\
\text { catheter }\end{array}$ \\
\hline Diameter (mm) & 13 & 13 & 10.4 & 3 \\
\hline Frequency $(\mathrm{MHz})$ & 7.5 & $7.5 / 12^{*}$ & 7.5 & 7 \\
\hline $\begin{array}{l}\text { Depth of } \\
\text { penetration }(\mathrm{cm})\end{array}$ & 10 & $10 / 3$ & 10 & 3 \\
\hline Axial resolution ( $\mathrm{mm}$ ) & 0.2 & $0.2 / 0.12$ & 0,2 & $?$ \\
\hline $\begin{array}{l}\text { EUS-guided } \\
\text { puncture/biopsy }\end{array}$ & No & Yes & No & No \\
\hline
\end{tabular}

-Switchable frequency. EUS Endoultrasonography 


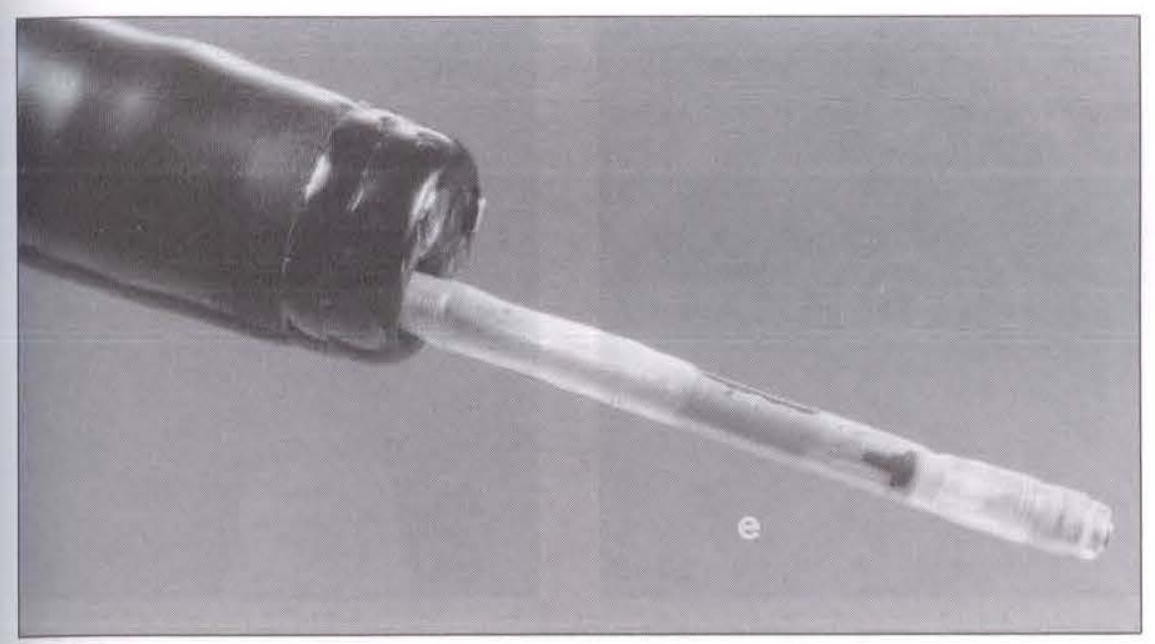

Figure 3) A minicatheter echoprobe (e) passing through the instrumental channel of a large calibre gastroscope for endoscopic-guided sonography

nonoptic instrument or an endoscopicguided catheter echoprobe can be used.

\section{INTERPRETATION OF ENDOSONOGRAPHIC IMAGES}

Sonographic interpretation of gastrointestinal wall structure and perigastrointestinal lymph nodes is based on results obtained through detailed examination of resected specimens and autopsy materials. In essence, endosonography visualizes a five layer structure, which shows close correlation with wall histology. An esophageal carcinoma is imaged as a hypoechoic echo pattern with partial or total destruction of the normal architecture. Endosonography criteria for assessment of the depth of tumour infiltration are summarized in Table 2 .

\section{TABLE 2}

\section{Endosonographic criteria for assessment of depth of esophageal tumour} infiltration

ES-TI Hypoechoic tumour localized in mucosa or submucosa

ES-T2 Hypoechoic tumour penetrating muscularis propria

ES-T3 Hypoechoic tumour with penetration into adventitia

ES-T4 Hypoechoic tumour with penetration into adjacent structures, eg, aorta, pericardium, trachea, diaphragm, liver

\section{TABLE 3}

Computed tomography criteria for the assessment of depth of esophageal tumour infiltration

CT-I1 (pTI + pT2) Wall thickness approximately $10 \mathrm{~mm}$

CI-T2 (PT3) Wall thickness greater than $10 \mathrm{~mm}$ with no evidence of invasion into adjacent structures (presence of fat plane)

CT-T3 (pT4) Wall thickness greater than $10 \mathrm{~mm}$ with evidence of invasion into adjacent structures (no fat plane)

For computed tomography staging. pII and pT2 are grouped together because computed tomography is not able to image the muscularis propria

\section{COMPARISON BETWEEN \\ ENDOSONOGRAPHY, COMPUTED TOMOGRAPHY AND HISTOLOGY}

Recently, a prospective study was performed with endosonography and computed tomography in 74 patients with esophageal carcinoma (20). The results of this preoperative study were correlated with the histology of resected specimens according to the new (1987) TNM classification.

In the assessment of the depth of tumour infiltration, endosonography is more accurate than computed tomography in diagnosing early stages (T1 + T2) and nonresectability (T4) of disease (Figures 4,5). The accuracy of endosonography in diagnosing $\mathrm{T} 1$ carcinoma was $88 \%$ and $\mathrm{T} 2$ carcinoma $78 \%$. The overall accuracy of endosonography and computed tomography for diagnosing early stages ( $\mathrm{T} 1$ and T2) were $82 \%$ and $12 \%$, respectively. The accuracy of endosonography and computed tomography in diagnosing T4 carcinoma was $90 \%$ and $64 \%$, respectively. In diagnosing T3 carcinomas the accuracy of endosonography was $93 \%$ versus $88 \%$ for computed tomography. This difference was not significant $(\mathrm{P}=0.48)$.

Endosonography is more accurate than computed tomography in diagnosing metastatic involvement of regional lymph nodes versus nonmetastatic lymph nodes (Figure 6). In contrast, computed tomography is more accurate in determining the presence of benign

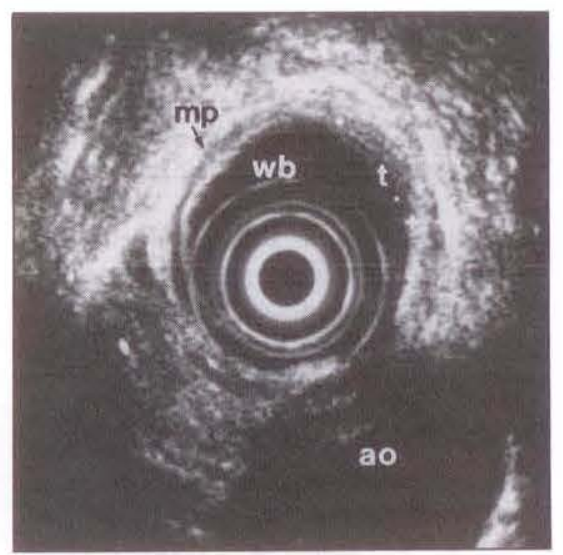

Figure 4) Endosonogram of a small intramural esophageal carcinoma $(t)$ penetrating into the muscularis propria ( $m p)$ localized ventrally. wb Water-filled balloon; ao Aorta 


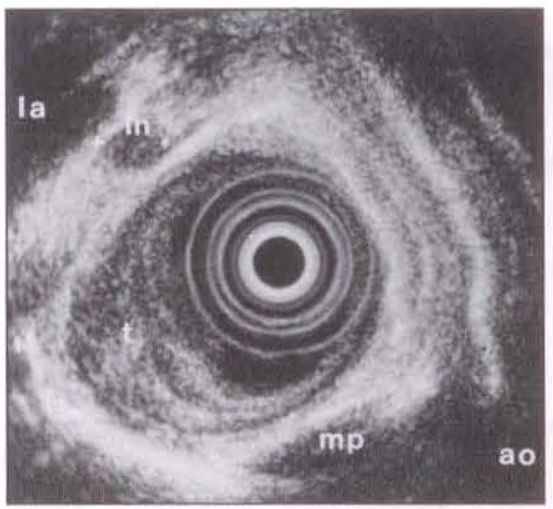

Figure 5) Endosonogram of a transmural carcinoma $(t)$ with penetration through the muscularis propria $(m p)$ into the adjacent adventitia, and a hypoechoic, clearly demarcated lymph node (ln) (diameter $8 \mathrm{~mm}$ ) suspect for metastatic involvement. la Left atrium

lymph nodes. Clinically, the diagnosis of lymph node metastasis is essential to selection of appropriate patients for surgery (Figure 6).

Endosonography is more accurate than computed tomography in diagnosing celiac lymph node metastasis (distant metastasis). Computed tomography, however, is more accurate than endosonography in diagnosing liver metastasis betause of the limited penetration depth of ultrasound.

In another study with a more extensive series of patients $(n=91)$ the accuracy of endosonography in diagnosing $\mathrm{T} 1$ carcinomas was $82 \%, \mathrm{~T} 2$ carcinomas $85 \%$, T3 carcinomas $94 \%$ and $\mathrm{T} 4$ carcinomas $92 \%$. Overstaging occurred in $6 \%$ and understaging in $4 \%$

\section{REFERENCES}

1. Yang GR, Huang $\mathrm{H}$, Qui SL, Chang YM. Endoscopic diagnosis of 115 cases of early esophageal carcinoma. Endoscopy 1982;14:15761.

2. Yang GR, Qui SL. Endoscopic surveys in high-risk and low-risk populations for esophageal cancer in China with special references to precursors of esophageal cancer. Endoscopy 1987;19:91-5.

3. Endo N, Takemoto T, Shirakabe H. Minute lesions of esophageal cancer. Semin Surg Oncol 1986;2:177-86.

4. Kabuto $T$, Taniguchi $K$, Iwanaga $T$, et al. Primary adenoid cystic carcinoma of the esophagus. Report of a case. Cancer 1979;43:2452-6.

5. Guanrei $Y$, Songliang Q, He H, Guizen
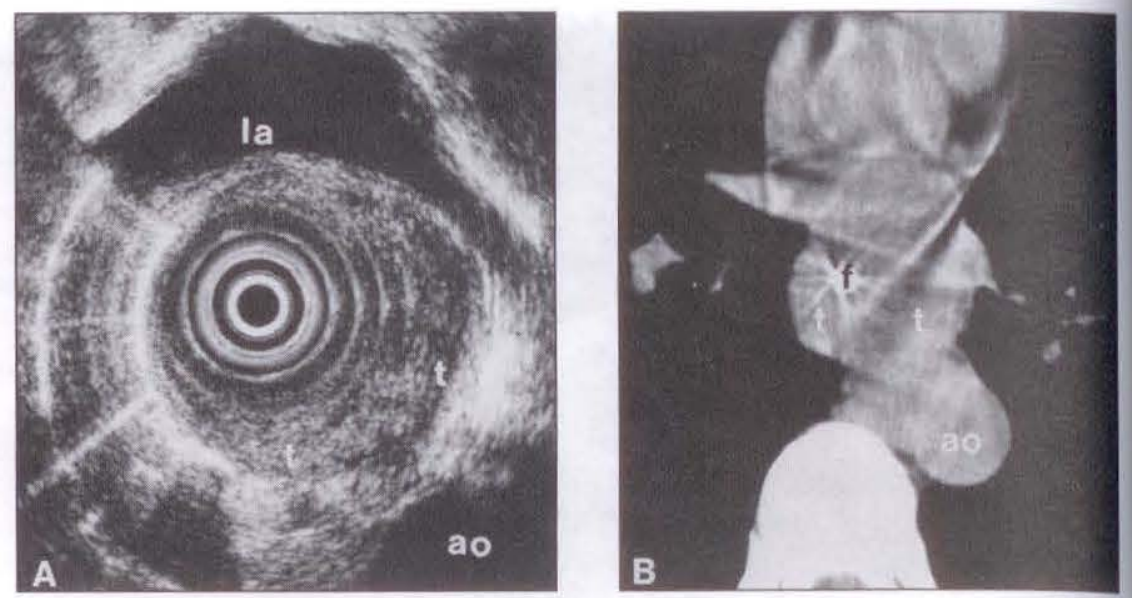

Figure 6) A Endosonogram of an extensive esophageal carcinoma ( $t$ ) with penetration into the aonta (ao). la Left atrium. B Corresponding computed tomography shows some thickening of the esophaged wall $(t)$ adjacent to the aorta with a feeding tube $(f)$ in the esophagus

(21). The results of staging regional lymph nodes and distant metastasis were comparable to those of the previous study.

\section{CONCLUSIONS}

Endosonography is more accurate than computed tomography in the preoperative TNM classification of esophageal carcinoma. However, inadequate examination of endosonography can occur in the presence of severe stenosis. Such obstructive tumours do not limit the role of computed tomography scanning. The recently available catheter echoprobe is promising for the staging of severe obstructed esophageal carcinoma. Moreover, endosonography staging can be performed during a routine endoscopic procedure.

Endosonography is accurate for stag. ing esophageal carcinomas indepen. dent of their localization. Computed tomography is not as reliable for staging carcinoma at the esophagocardial junction as for staging esophageal carcinoma The routine use of endosonography-guided cytology for tissue diagnosis, particularly lymph node metastasis, will further enhance the diagnostic value of endosonography. Moreover, the combination of endosonography and Doppler probe, which has already been introduced in cardiology, will further increase the value of endosonography in assessing vascular abnormalities $(22,23)$.

CL, Owen JW. Computed tomography in the staging of esophageal carcinoma Radiology 1983;146:433-8.

squamous carcinoma and early adenocarcinoma of the gastric cardia in the People's Republic of China. Endoscopy 1988;20:95-8.

6. Hermanek P, Sobin LH. TNM Classification of Malignant Tumours, 4th edn. Heidelberg: Springer-Verlag, 1987.

7. Sobin LH, Hermanek P, Hutter RVP. TNM-classification of malignant tumours. A comparison between the new (1987) and the old editions. Cancer 1988;6:2310-4.

8. Japanese Committee for Registration of Esophageal Carcinoma. A proposal for a new TNM classification of esophageal carcinoma. Jpn J Clin Oncol 1985; 14:385-410.

9. Picus D, Balfe DM, Koehler RE, Roper
10. Quit LM, Glazer GM, Orringer MB, Gross BH. Esophageal carcinoma: Computed tomography findings. Radiology 1985;155:171-5.

11. Tio TL, Tytgat GNJ. Endoscopic ultrasonography in the assessment of intra- and transmural infiltration of tumours in the oesophagus and papilla of Vater and in the detection of extraoesophageal lesions. Endoscopy 1984;16:203-10.

12. Tio TL, Tytgat GNJ. Endoscopic ultrasonography of normal and structure. Comparison of studies in vivo and in vitro with histology. Scand J Gastroenterol 1986;21 pathologic upper gastrointestinal wall 
(Suppl 123):27-33.

13. Tio TL, Tytgat GNJ. Endoscopic ultrasonography in analysing periintestinal lymph node abnormality. Scand J Gastroenterol 1986;21 (Suppl 123):158-63.

14. Tio TL, den Hartog Jager FCA, Tytgat GNJ. Endoscopic ultrasonography of non-Hodgkin lymphoma of the stomach. Gastroenterology 1986;91:401-8.

15. Tio TL, den Hartog Jager FCA, Tytgat GNJ. The role of endoscopic ultrasonography in assessing local resectability of esophagogastric malig. nancies. Accuracy, pitfalls and predictability. Scand J Gastroenterol 1986;21(Suppl 123):78-86.

16. Tio TL, Tytgat GNJ. Atlas of Trans- intestinal Ultrasonography. Aalsmeer: Mur-Kostverloren, 1986.

17. Takemoto T, Aibe T, Fuji T, Okita K. Endoscopic ultrasonography. Clin Gastroenterol 1986;15:305-19.

18. Murata Y, Muroi M, Yoshida M, Ide H, Hanyo F. Endoscopic ultrasonography in the diagnosis of esophageal carcinoma. Surg Endosc 1987;1:11-6.

19. Yasuda K, Kiyota K, Nakayima M, Kawai K. Fundamentals of endoscopic laser therapy for GI-tumours. New aspect with endoscopic ultrasonography (EUS). Endoscopy 1987;19:2-6.

20. Tio TL, Cohen P, Coene PP, Udding J, den Hartog Jager FCA, Tytgat GNJ. Endosonography and computed tomography of esophageal carcinoma:
Preoperative classification compared to the new (1987) TNM classification. Gastroenterology 1989;96:1478-86.

21. Tio TL, Coene PPLO, Schouwink $\mathrm{MH}$, Tytgat GN]. Esophagogastric carcinoma: Preoperative TNM classification with endosonography. Radiology 1989;173:411-7.

22. Parisi AF, Nieminen M, O'Boyle JE. Enhanced detection of the evaluation of tissue changes after acute myocardial infarction using colour encoded two dimensional echocardiography. Circulation 1982;66:764-70.

23. Martin RW, Gilbert DA, Silverstein FF, Delterne M, Tytgat GNJ. An endoscopic Doppler probe for assessing intestinal vasculature. Ultrasound Med Biol 1983;11:61-9. 


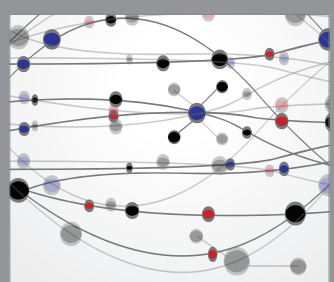

The Scientific World Journal
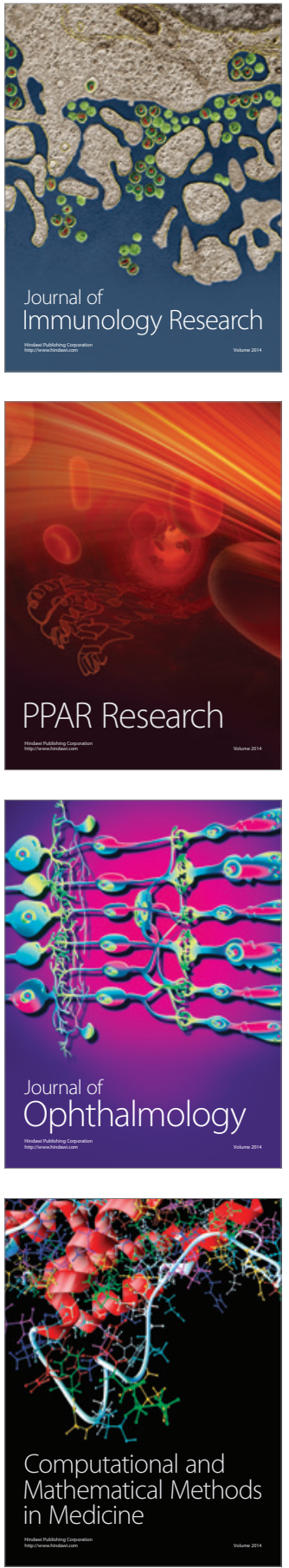

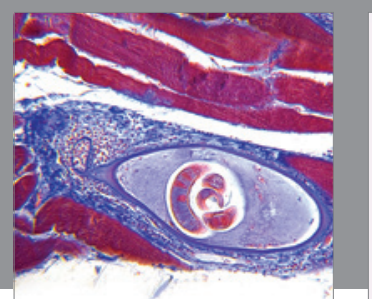

Gastroenterology Research and Practice

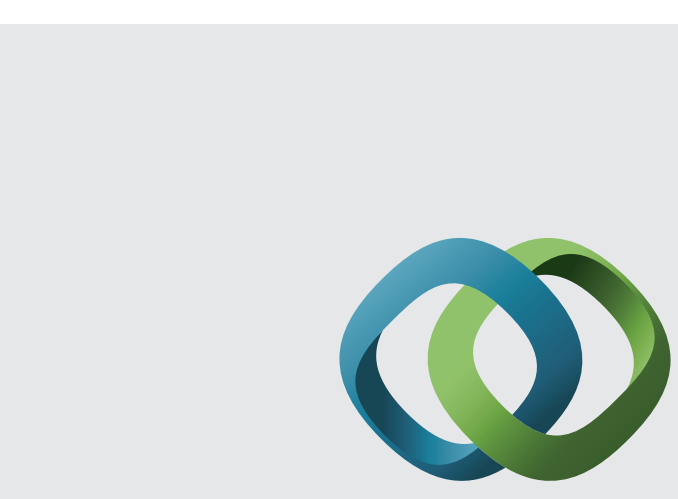

\section{Hindawi}

Submit your manuscripts at

http://www.hindawi.com
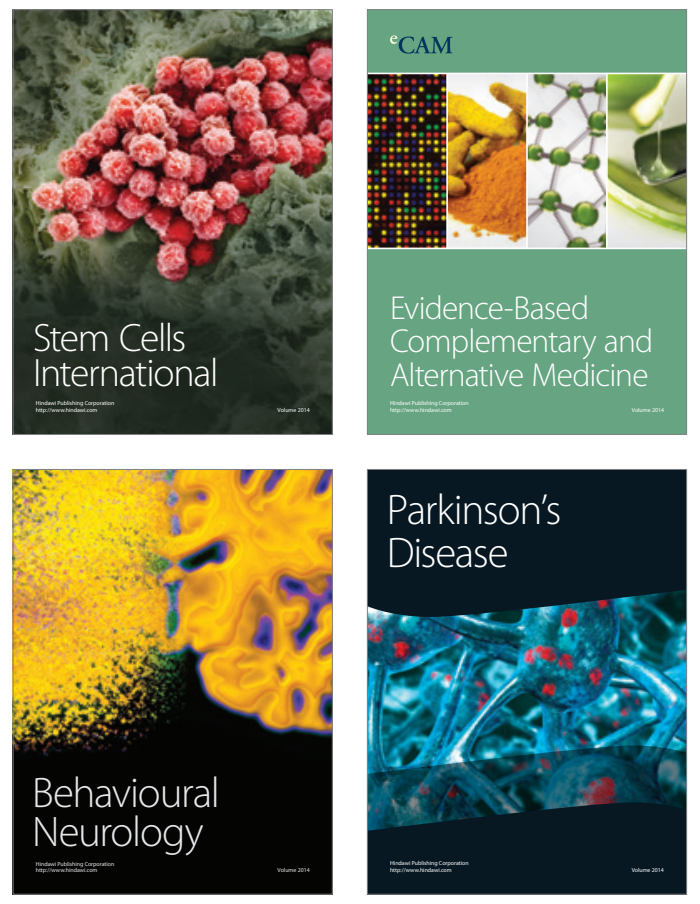
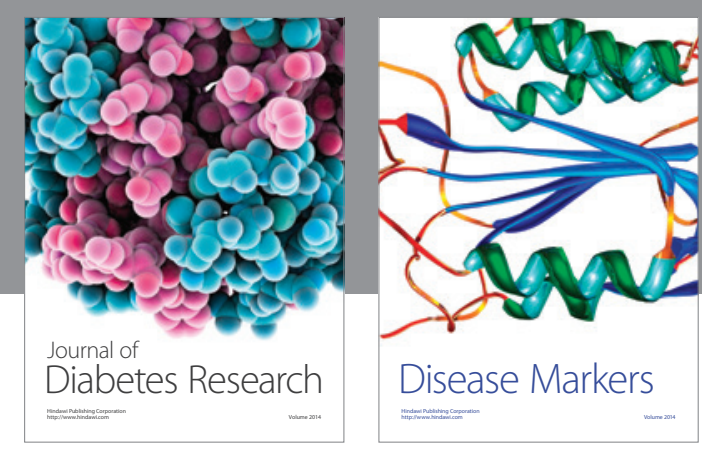

Disease Markers
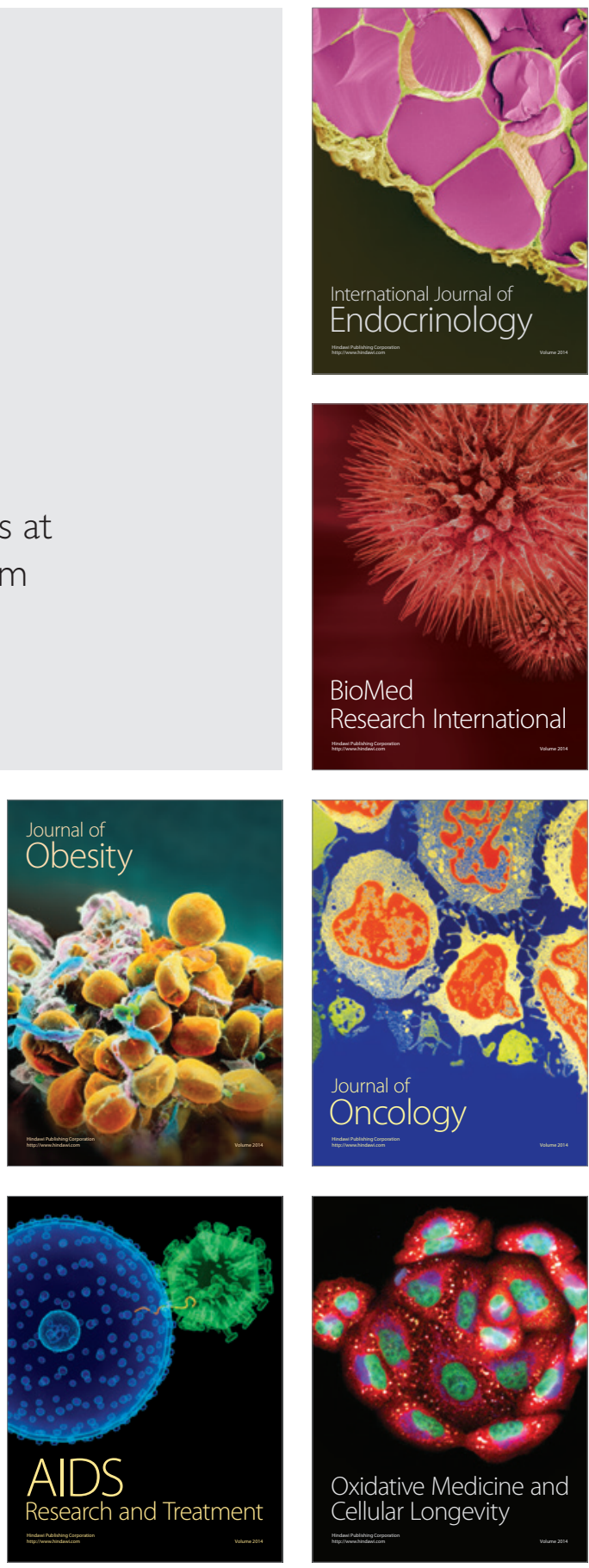